\title{
Design and Development of an Electric Remote-Controlled Road-Sweeper Vehicle ${ }^{\dagger}$
}

\author{
Sunil Jamil *, Talha Mukhtar (D, Rana Hamas Ali, Irfan Qaiser and Burhan Ahmed
}

Department of Electrical Engineering, University of Gujrat, Gujrat 50700, Punjab, Pakistan; talhaawan43@gmail.com (T.M.); ranahamas1990@gmail.com (R.H.A.); Irfan.qaiser@uog.edu.pk (I.Q.); Engrahmedch2911@gmail.com (B.A.)

* Correspondence: suniljamil999@gmail.com

† Presented at the 1st International Conference on Energy, Power, and Environment, Gujrat, Pakistan, 11-12 November 2021.

check for updates

Citation: Jamil, S.; Mukhtar, T.; Ali, R.H.; Qaiser, I.; Ahmed, B. Design and Development of an Electric RemoteControlled Road-Sweeper Vehicle. Eng. Proc. 2021, 12, 89. https://doi.org/ 10.3390/engproc2021012089

Academic Editor: Qasim Awais

Published: 18 January 2022

Publisher's Note: MDPI stays neutral with regard to jurisdictional claims in published maps and institutional affiliations.

Copyright: (C) 2022 by the authors. Licensee MDPI, Basel, Switzerland. This article is an open access article distributed under the terms and conditions of the Creative Commons Attribution (CC BY) license (https:// creativecommons.org/licenses/by/ $4.0 /)$.
Abstract: Dirty surroundings impose a detrimental effect on the beauty of our environment. Hiring and paying for a large workforce to clean the debris on the roads, parks, and streets is a costly and tiring job. This project has been carried out to design and fabricate a battery-powered road-sweeper vehicle (RSV), equipped with a scrubber system. The proposed machine, equipped with scrubbers, increases the operational time while decreasing the operational cost. In contrast with typical industrial counterparts, an eco-friendly road-sweeper machine is presented in this study.

Keywords: mechanical broom sweeper; electrical road-sweeper vehicle; BLDC motor; BLDC motor driver CH12 wireless communication; LN298; geared DC motor

\section{Introduction}

For decades, manufacturers and end-users alike have been absorbed by the challenge of keeping our surroundings clean and tidy. Hiring and paying for a large workforce to clean debris on the roads, parks, and streets is a very costly, time-consuming, and tiring job. Moreover, the initial and maintenance costs of gasoline-powered road-sweeper vehicles are very high. These road-sweeping vehicles are not eco-friendly, running on combustion engines and producing noise that renders these vehicles inappropriate to be used in places such as universities, hospitals, and airports to name a few. Machines and tools used for the collection of debris can typically be divided into three types: mechanical broom sweepers, vacuum sweepers, and regenerative air sweepers.

\section{Previous Work}

Although each type of street sweeper achieves the same goal-removing debris from paths - they all have unique benefits for different types of debris and roads that they operate on. As in [1], authors have described a novel method for road cleaning by merging the scrubbing system with suction, especially suitable for Indian road conditions. Ref. [2] deals with the use of an electric vehicle for sweeping and vacuum purposes, and [3] proposes the design, structure, and working of a multipurpose cleaning machine implemented with a vacuum part. In [4], the vehicle presented is autonomous and uses brushes in combination with a vacuum to perform the cleaning task. In [5], it is stated that the main difficulties in developing a sweeping robot are that the general characteristics of the sweeping brushes are not well known. In [6], a portable sweeping machine was developed from locally sourced raw materials to sweep and clean public places like markets, parks, gardens, etc., as part of the measures to prevent the further spread of COVID-19 in public places. 


\section{Methodology}

The present work is aimed for the design, development, and evaluation of a manually, as well as a remotely, operated mechanical broom sweeper electrical road-cleaning machine, dedicated to the aforementioned places littered with junk food covers, cold drinks bottles, leaves, etc., where cleaning is an important parameter for sanitation and government regulations.

\subsection{Modeling the Structure of the Vehicle}

This CAD design was prepared in Autodesk AutoCAD. Figure 1 below gives the idea of the proposed design.

\section{Antenna}

2. Power and Control Circuitry

3. The see-through window for debris in the trash-can

4. 36v Charging plug

5. Brushless DC wheel hub motors

6. Scrubber brush coupled with a DC-geared motor

7. Caster wheels

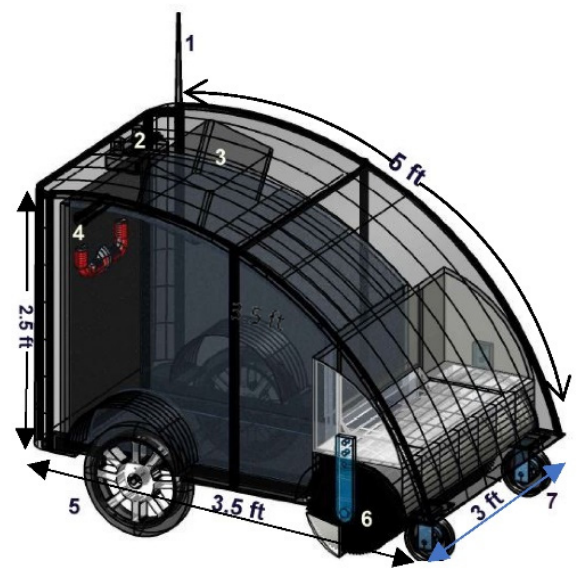

Figure 1. AutoCAD Design.

\subsection{Mechanical Structure}

The basic support structure of the vehicle is made of iron sheets and columns. The base of the vehicle is made of an iron sheet that is easy to bend, and has the required strength to bear the weight of the waste storage and other electrical equipment. The upper roof is made of acrylic sheets that provide a finer look, as well as hide the structural asymmetry, and save the electronic equipment from weather and dust. Figure 2, provides the actual picture of the finished product.

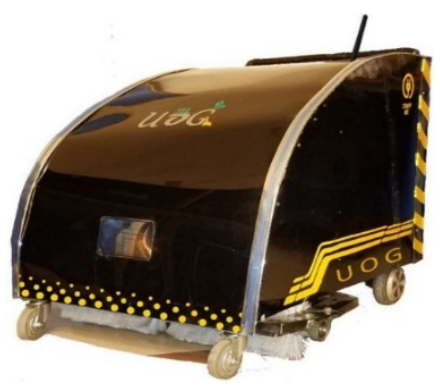

Figure 2. Mechanical Structure. 


\section{Power Consumption}

The two motors used for propulsion only consume 300 watts of power, with each motor consuming 150 watts. The DC motor, which rotates the brush, only consumes 20 watts. So, this road-sweeper vehicle utilizes only 320 watts of power, which is equivalent to 0.435079 horsepower: reasonably less than the power consumed by a commercially available road sweeper operating on the combustion engine.

\subsection{Block Diagram}

A block diagram of the circuitry is given in Figure 3. The controlling circuitry of the road sweeper utilizes the $\mathrm{CH} 12$ wireless module, whose range is one kilometer in the open air. This road sweeper uses BLDC wheel hub motors, which are $40 \%$ more power-efficient than the same rated DC-geared motor.

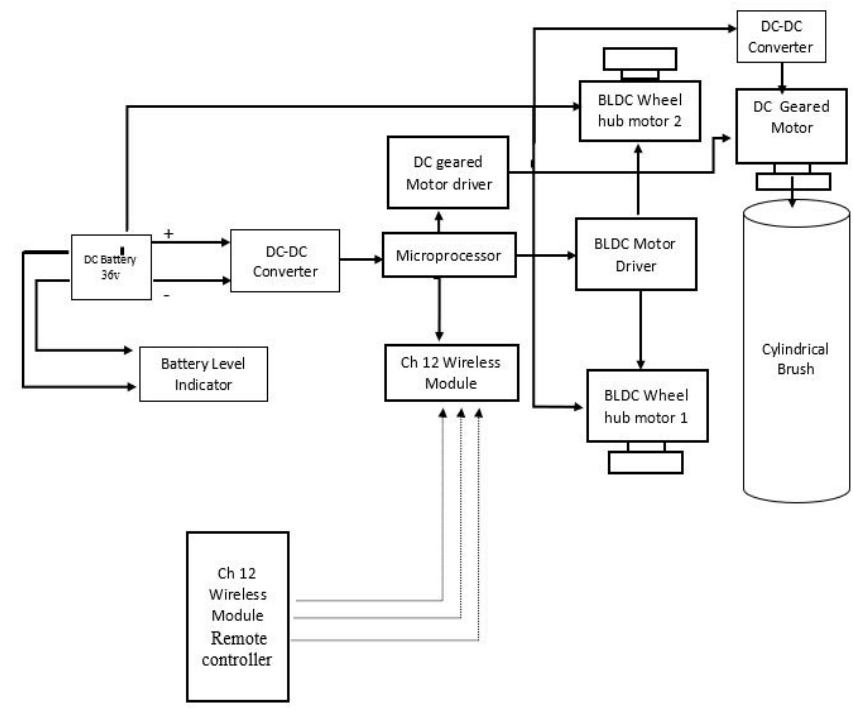

Figure 3. Block Diagram of the Circuitry.

\subsection{Simulation}

BLDC Transient Analysis

Microprocessor PIC16F877 has been used for simulation purposes of the BLDC used. Figure 4 below shows the schematics for the control of BLDC. 


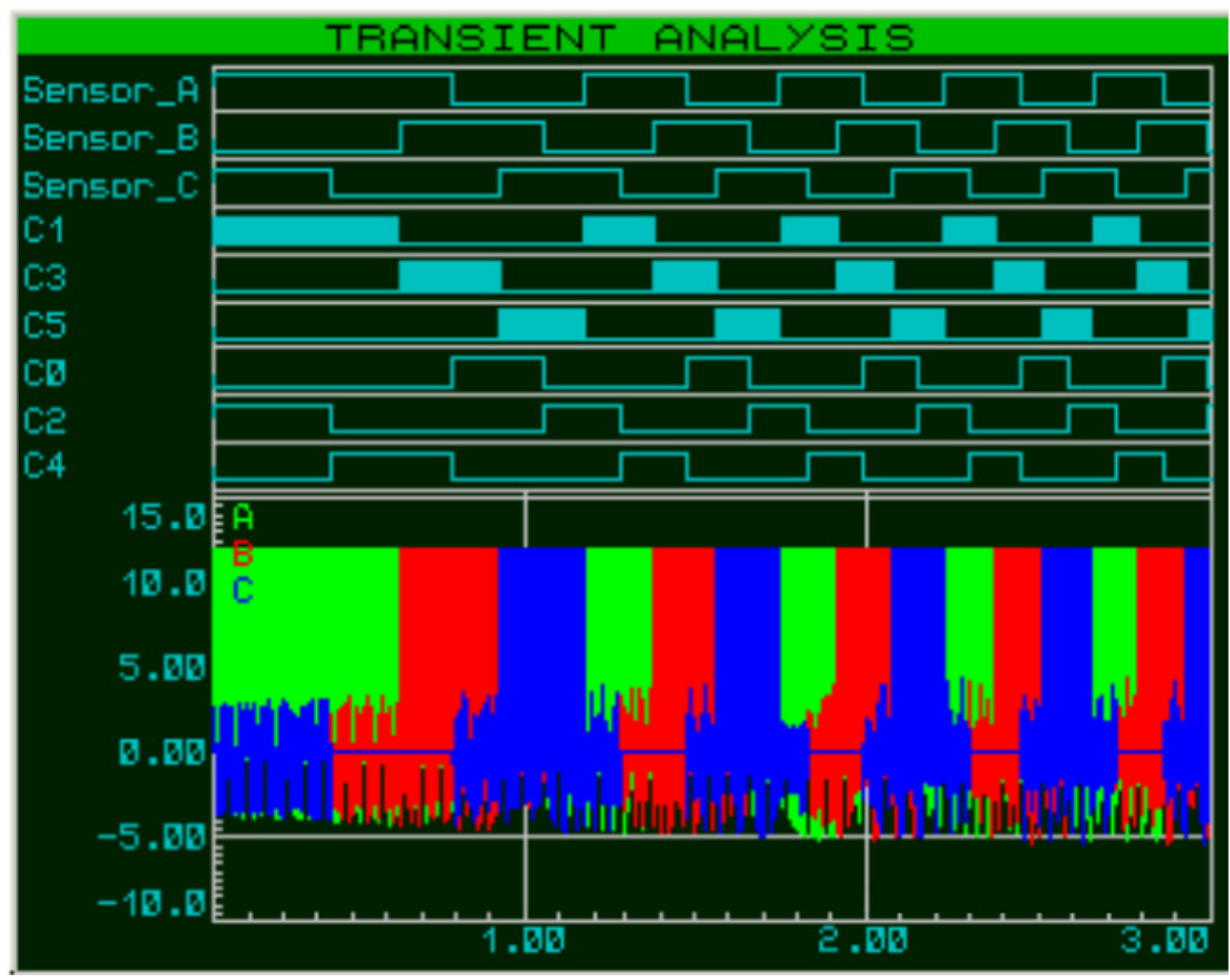

Figure 4. Transient analysis of the BLDC.

\section{Results}

The shaft motor of the sweeper vehicle is 20 watts. Referring to Figure 5 since there were two BLDC motors used in the vehicle, the total power consumption of the vehicle can be observed in Figure 5, as follows.

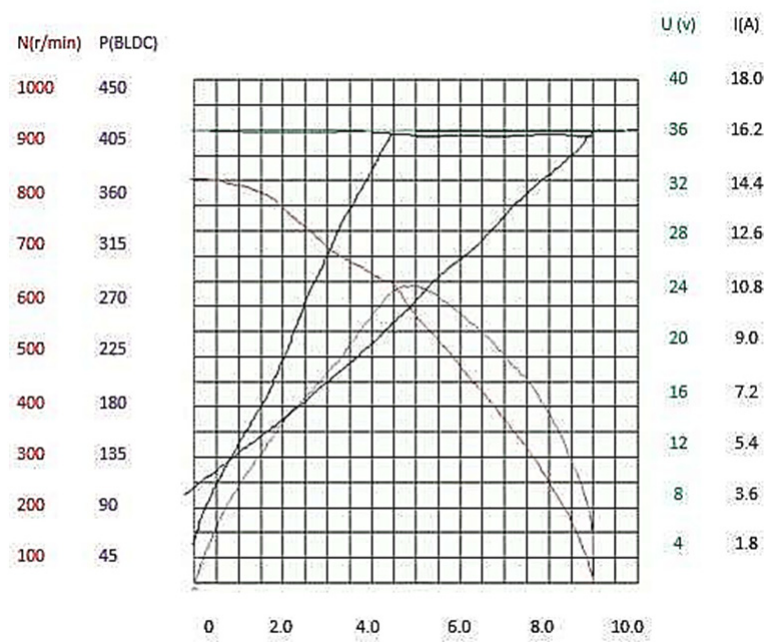

Figure 5. Simulation Results.

\section{Comparison}

To evaluate it's performance and other parameters a comparison table is given in Table 1. It provides the comparison, of our vehicle against it's already developed counterparts, based on several parameters. 
Table 1. Comparison with other road sweepers.

\begin{tabular}{cccccccc}
\hline $\begin{array}{c}\text { Features/ } \\
\text { Parameters }\end{array}$ & Reference [1] & Reference [2] & Reference [3] & Reference [4] & Reference [5] & Reference [6] & $\begin{array}{c}\text { Our } \\
\text { Machine }\end{array}$ \\
\hline Maneuverability & Good & Good & Satisfactory & Satisfactory & Satisfactory & Good & Good \\
\hline Power source & Fuel & None & Electric & Electric & Electric & Fuel & Electric \\
\hline Echo Friendly & NO & YES & YES & YES & YES & NO & YES \\
\hline Vacuum/ brush & Both & Brush only & Brush only & Brush only & Brush only & Brushes & Brushes \\
\hline Sweeping Ability & Good & Satisfactory & Satisfactory & Satisfactory & Good & Good & Good \\
\hline Applicability & Urban roads & Streets and & Streets and & Streets and & All & All & All \\
\hline Maintenance & Often & Very less & Often & Often & Often & Very Less & Very Less \\
\hline Auto/Manual & Manual & Manual & Manual & Autonomous & Semi-Auto & Manual & Manual \\
\hline
\end{tabular}

\section{Conclusions}

The vehicle is moved by two BLDC motors, which make its operation noiseless. It is electric, and hence does not have any carbon emissions or other hazardous substances, making it completely environment friendly. The vehicle is a lot easier to transport and operate than others of its kind, and it is hundreds of times less costly than market available versions. It only needs 36-volt battery charging and does not consume any fuel, thus reducing its operational cost. The vehicle is controlled by the radio frequency module, which has a range of more than $1 \mathrm{~km}$ in open space. Thus, the person operating it can stand and clean a large area from a distance, reducing levels of tiredness in workers.

Funding: This research received no external funding.

Institutional Review Board Statement: Not applicable.

Informed Consent Statement: Not applicable.

Data Availability Statement: Not applicable.

Conflicts of Interest: The authors declare no conflict of interest.

\section{References}

1. Mukesh, A.V.V.; Rao, M.V.; Chaitanya, M.S.R.K. Design and Development of Simplified Road Cleaning Machine with Modified Technology Suitable to Indian Environment. IJESR 2016, 4, 97.

2. Avinash, P.; Kaushik, S.; Prakash, P.; Haridasan, H.; Balamurugan, S.; Vignesh, S. Design \& construction of manually operated electric road cleaner. Int. J. Res. Appl. Sci. Eng. Technol. (IJRASET) 2014, 1, 113-121.

3. Khan, A.; Pannase, A.; Sharnagat, A.; Gohan, G. Study of Multipurpose Road Cleaning Machine. Int. Res. J. Eng. Technol. (IRJET) 2017, 4, 1382-1386.

4. Jeon, J.; Jung, B.; Koo, J.C.; Choi, H.R.; Moon, H. Autonomous Robotic Street Sweeping: Initial Attempt for Curbside Sweeping. In Proceedings of the 2017 IEEE International Conference on Consumer Electronics (ICCE), Las Vegas, NV, USA, 8-10 January 2017.

5. Wang, C.; Parker, G. Analysis of Rotary Brush Control Characteristics for a Road Sweeping Robot Vehicle. In Proceedings of the 2014 International Conference on Mechatronics and Control (ICMC), Jinzhou, China, 3-5 July 2014.

6. Adedeji, K.A. Design, and construction of a street sweeping machine. Int. J. Eng. Appl. Sci. Technol. 2020, 5, 626-630. 